handelt man dagegen die Legirung mil Salpetersäure, trennt das gelbliche unlösliche Gemenge von Zinnoxyd und antimoniger Säure, gluibt es, wobei es grïnlich wird, und behandelt es mit Schwefelsäure und Wasser (und Zink? Die B ed.), so erhält man eine reichliche Entwickelung von Antimonwasserstoffgas und beim Anzünden guosse glänzende Antimonflecken. (Journ. de Chim. med. 1844. Pharm. Centralbl. No. 25. 1844) B.

\title{
Ueber Goldehlorid.
}

Lm dic früher mil Schwierigkeit verbundene Auflösung des Goldes leicht zu bewirken, übergiesst man das durch Antimonchlorïr gefällte Gold mit dem doppelten Gewicht eines Gemisches aus 3 Theilen Salzsäure, $1 \mathrm{Th}$. Salpetersäure und 1 Th. destillirten Wassers (das ligengewicht der Siuren ist nicht angegeben) und erwärmt das Ganze so lange in einer concentrirten Kochsalzauflösung, bis keine Dämpfe von salpetriger Säure mehr erscheinen. Ist nicht alles Gold aulgelöst, so giesst man von dem Säuregemisch bis zum Verschwinden des ersteren allmälig hinzu und verdampft die Flüssigkeit so weit, bis eine darin eingetauchte Glasstange nach dem Herausziehen darauf erstarrtes Goldchlorid anzeigt. In dem Gefässe erscheinen dann beim Erkaiten desselben sehr bald prismatische Nadeln von schöner Orangefarhe. Diese lösen sich vollstiandig und ohne Reduction in Wasser auf und dienen dann unter Anderm vortrefflich zur Fixirung der Dauguerrotypbilder, u. s. w.

Das rothe Goldchlorid wird anf eben diese Weise dargestellt, nur muss man hierzu ein Gemisch von zwei Th. Salzsäure und einem 'Th. Salpetersäure, und im Anfang der Auflösung stärkere Wärme anwenden. (Journ. de Pharm. et de Chim. Mai 1844. p. 392.) Du Menil.

\section{Platinschwamm in den Döbereiner'schen Züıd- maschinen.}

Dr. Böttger hat die Beobachtung gemacht, dass bei Anwendung der rauchenden oder Nordhäuser Schwefelsäure zu den Döberciner'schen Zündmaschinen der Platinschwamm viel eher seine Zündkraft verliert, als wenn englische Schwefelsäure dazu verwandt wird. Als Grund

bleibt zurück. Diese Scheidung mit Salasüure gelingt aber nur, wenn dis Zinn zu dem Antimon in einem stöchiometrischen Verluältnisse von mindestens 20 Aeq. : 1 Aeq. stebt. IIr. Wr. 
wird angegeben, dass die rauchende Schwefelsäure fast ohne Ausnahme beim Vermischen mit Wasser schweflige Säure entwickele, die dann durch Wasserstoffgas zum Theil in Schwefelwasserstoffgas ubergeführt wird, dieses aber höchst nachtheilig für den Platinschwamm sei und denselben in kurzer Zeit ganz unbrauchbar mache.

Wenn auch die auf langjährige Beobachtungen gestiitzten Angaben Böttger's, dass einige Gasarten, namentlich Schwefelwasserstoffgas, höchst nachtheilig auf den Platinschwamm wirken und diesem die Zündkraft rauben, keineswegs bezweifelt werden und als richtig anerkannt werden müssen, so möchte doch wohl in den wenigsten Fällen, wenn eine derartige Zuindmaschine ihren Dienst versagt, die Ursache davon rauchende Schwefelsäure und das hierdurch erzeugte Schwefelwasserstoffgas sein, da diese Säure des höhern Preises wegen wohl selten zum Füllen der Zündmaschinen gebraucht, vielmehr die englische Schwefelsäure dazu verwandt wird.

Sehr häufig werden aber auch diejenigen Zündmaschinen unbrauchbar, die mit verduinnter englischer Schwefelsäure gefüllt sind. Es rührt dieses bekanntlich her von einer Verunreinigung der Säure mit Arsen, indem sich alsdann Arsenwasserstoffgas entwickelt, welches höchst nachtheilig auf die Ziindkraft des Platinschwämmchens wirkt. (Journ. fiir prakt. Chem. B.30.p.272.) Overbeck.

\section{Darstellung der Zirkonerde.}

Wenn man reinen Zirkon mit der 4fachen Gewichtsmenge kohlensauren Natrons in einem Platintiegel schmilzt, so kann man nach $T h$. Sch e erer durch Aufweichen der Masse mit Wasser kieselsaures Natron ausziehen und suspendirtes Eisenoxyd abschlämmen. Das hinterbleibende krystallinische Zirkonerde-Natron löst sich leicht in Salzsäure auf. Die Aufösung giebt mit Ammoniak schneeweisses Zirkonerdehydrat. (Annal.d. Phys. u. Chem. Bd.59. p. 48r.) $H$. Wr.

Scheerer macht noch besonders darauf aufmerksam, dass das Zirkonerde-Natron nicht zu lange mit Wasser ausgesüsst werden müsse, weil sich dann ein Theil Zirkonerde als die in Säuren unlösliche Modification derselben abscheide. Daraus geht hervor, dass die Zirkonerde nicht allein aus ihren Verbindungen mit Säuren ( $\mathrm{s}$. Poggendorff's Ann. XLVIII. p. 575), sondern auch aus denen mit Alkalien durch Wasser abgeschieden wird. Wahr- 